\title{
EXPERIÊNCIAS COM FERRAMENTAS DIGITAIS NO ENSINO DE ESTRUTURAS ARQUITETÔNICAS
}

\author{
EXPERIENCES WITH DIGITAL TOOLS IN TEACHING ARCHITECTURAL STRUCTURES
}

\author{
Felipe Tavares da Silva ${ }^{1}$ \\ 'Universidade Federal da Paraíba, João \\ Pessoa, PB, Brasil, \\ felipe.tavares@academico.ufpb.br
}

\begin{abstract}
Contribuição do autor:
FTS: conceituação, curadoria de dados, análise formal, investigação, metodologia, administração de projetos, programas, validação, visualização, escrita - rascunho original, escrita - revisão e edição.
\end{abstract}

Fomento: Não houve fomento Declaração de conflito: nada foi declarado.

Editor Responsável:

Regina Coeli Ruschel (ic)

\begin{abstract}
Resumo
Entre 2011 e 2019, o conjunto das disciplinas de Estruturas de um curso de graduação em Arquitetura foi conduzido com experiências metodológicas incorporando simulações estruturais computacionais, aqui sumarizadas. As disciplinas têm ementas com temas que vão da mecânica e simulação estrutural; concepção estrutural; projeto e detalhamento de estruturas em concreto armado, em aço e em madeira. Foi utilizada nesta experiência o método de pesquisa-ação e alguns conceitos do design science e do design science research, com o objetivo de aprimorar o ensino de estruturas para arquitetos e incorporar a concepção e projeto estrutural nas fases iniciais de projeto de arquitetura. A proposta de pesquisa surge a partir da imprecisão e incompletude dos métodos tradicionais de prédimensionamento estrutural e a frequente desconexão entre a concepção estrutural e o projeto do espaço arquitetônico. Foram desenvolvidas concepções estruturais sobre concepções arquitetônicas desenvolvidas em disciplinas de Projeto de Arquitetura conduzida por professores arquitetos, sendo assim posto o desafio de contemplar na concepção estrutural o programa arquitetônico e a viabilidade técnica da concepção estrutural, qualitativamente e quantitativamente. Esta experiência apontou que, alunos capacitados no uso de simuladores estruturais projetaram com uma consciência clara e profissional sobre a concepção Estrutural junto à Arquitetura, ao passo que verificaram a aceitabilidade estrutural com precisão. No entanto, de modo que se possa atingir uma plenitude da transdisciplinaridade no processo de projeto de edifícios, o uso destes recursos adicionais demanda uma maior integração entre as disciplinas de estruturas e as disciplinas que lidam com conteúdo em comum: matemática; geometria, lógica de programação e projeto arquitetônico.
\end{abstract}

Palavras-chave: Ensino de estruturas. Concepção Estrutural. Simulação estrutural. Projeto de Arquitetura.

\begin{abstract}
Between 2011 and 2019, the set of Building Structures disciplines of an undergraduate course in Architecture was conducted with methodological experiences incorporating computational structural simulations, summarized here. The disciplines have themes ranging from mechanics and structural simulation to structural design, reinforced concrete detailing, and steel and timber structures. In this experiment, the action research method and some concepts of design science and design science research were used to improve the teaching of structures for architects and incorporate structural design in the early stages of architectural design. The motivation arises from the imprecision and incompleteness of traditional preliminary structural design methods and the disconnection between the structural and architectural space design. Structural conceptions were developed for architectural conceptions developed in Architectural Design classes conducted by architecture teachers. Thus, posing the challenge of considering the structural design associated with the architectural program and the technical feasibility of the structural design, qualitatively and quantitatively. This experience pointed out that students trained in structural simulators designed with a clear and professional awareness of Structural design for Architecture and were able to check structural acceptability accurately. However, so that fullness of transdisciplinary in the building design process can be achieved, the use of these additional resources demands greater integration between the disciplines of structures and those that deal with common contents: mathematics, geometry, programming logic and architectural design.
\end{abstract}

Keywords: Teaching structures. Structural preliminary design. Structural simulation. Architecture design.

How to cite this article:

SILVA, F. T. da. Experiências com ferramentas digitais no ensino de estruturas arquitetônicas. PARC Pesquisa em Arquitetura e Construção, Campinas, SP, v. 12, p. e021022, 2021. DOI: http://dx.doi.org/10.20396/parc.v12i00.8661548 


\section{Introdução}

A experiência aqui relatada trata da incorporação de simulações estruturais em um conjunto sequencial de disciplinas de sistemas estruturais de um curso de graduação em Arquitetura entre 2011 e 2019. No ensino tradicional de estruturas em cursos de graduação em arquitetura geralmente são utilizadas maquetes estruturais para o estudo básico do comportamento elástico estrutural (OLIVEIRA, 2008; LOBOSCO; CÂMARA, 2018); a apresentação de diversas tipologias de sistemas estruturais para cada escala e tipo e escala de edificação (ENGEL, 2001); e o pré-dimensionamento das espessuras estruturais utilizando ábacos e percentuais com a correlação entre os vãos e as espessuras estruturais (CORKILL, 1969; MACDONALD, 2001; ENGEL, 2001; ALLEN; IANO,2017; REBELLO, 2007; MOUSSAVI, 2009; CHING; ONOUYE; ZUBERBUHLER, 2015). Em algumas poucas escolas de Arquitetura é abordado o cálculo dos esforços e deslocamentos estruturais, sendo geralmente realizados manualmente apenas casos simples (SARAMAGO, 2011), sem uso frequente de simuladores digitais de Estruturas.

A maquete estrutural tem o seu valor de visualização espacial e tridimensional, de observância do comportamento deformável de peças submetidas a forças impostas com as próprias mãos, de visualização da hierarquia estrutural em alguns sistemas, na verificação da lógica de um processo de montagem estrutural, dentre outras qualidades. Contudo, materiais usados em maquetes não são apropriados para verificar a aceitabilidade mecânica-estrutural de uma determinada proposta de projeto de estrutura real com materiais de construção reais, ou até mesmo da avaliação sobre sua estabilidade. Estas maquetes são bastante úteis para o aprendizado inicial, para o desenvolvimento de da intuição do funcionamento mecânico ou, no máximo, para uma discussão extremamente preliminar sobre o funcionamento básico de um determinado sistema estrutural. Para se projetar uma estrutura precisa-se da quantificação dos resultados sobre a aceitabilidade mecânica estrutural e também de seus deslocamentos e sobre a sua estabilidade à flambagem. Igualmente importante é a avaliação do impacto que a solução projetual tem no consumo de materiais. Estas informações não podem ser acessadas por maquetes estruturais.

No Brasil, o Conselho de Arquitetura e Urbanismo (CAU) dispõe sobre as atribuições profissionais do Arquiteto e Urbanista segundo a Lei Federal 12.378/2010, sendo a lei que regulamenta o exercício desta profissão e cria este conselho. O CAU por sua vez publicou a Resolução Interna $\mathrm{N}^{\circ} 21 / 2012$ em que ratifica e detalha quais seriam as atribuições desta profissão. No Art. 2 desta Lei, parágrafo único, inciso VIII, há a descrição da atuação do desenvolvimento de sistemas estruturais e desenvolvimento tecnológico de estruturas, sendo especificado em outros incisos a definição de outras atribuições como: concepção e execução de projetos, estudo de viabilidade técnica, elaboração de orçamento, dentre outros.

Com estas atribuições de poder conceber, projetar e executar estruturas arquitetônicas, a formação do Arquiteto precisa ser sólida suficientemente desde a compreensão básica e intuições do funcionamento mecânico até o aprofundamento necessário e suficiente para o detalhamento de um projeto para ser executado numa construção. O uso de ferramentas digitais, desde há algumas décadas, é largamente usado em escritórios de projetos de estruturas, sendo primordial a compreensão e domínio básico de sua operação por parte de Arquitetos: tanto para uma melhoria na comunicação numa equipe transdisciplinar de projeto caso o Arquiteto não se coloque na posição de concepção e projeto estrutural; quanto para o caso em que o Arquiteto se coloque nesta posição de definição e detalhamento da estrutura de um edifício. 


\section{A concepção estrutural no projeto de arquitetura}

$\mathrm{Na}$ concepção de estruturas é imprescindível construir um repertório de sistemas estruturais adequado a determinadas faixas de magnitude de vãos e às tipologias de suas formas geométricas, para relacioná-las com as geometrias das formas dos edifícios e suas relações com o espaço arquitetônico. Geralmente, isto é proposto no ensino através da apresentação de sistemas clássicos de peças de alma cheia, em treliça, em cascas, em pórticos, entre outros, catalogados em alguns livros do tema ou construções realizadas com imagens disponíveis na internet.

$\mathrm{Na}$ concepção estrutural tradicional, após se definir a tipologia do sistema são prédimensionadas as espessuras das suas peças, isto é, definem-se preliminarmente as dimensões das seções transversais dos membros estruturais. Para verificar se a estrutura atende às condições dos Estados Limites, precisa-se determinar os esforços e deslocamentos máximos, somente possível com as dimensões da seção transversal das peças.

Com um pré-dimensionamento, tem-se automaticamente a estimativa da quantidade de material estrutural e, assim, pode-se verificar se a taxa de consumo de material está em nível aceitável a partir de algum referencial de construção local. Ainda há uma essencial necessidade de saber se as espessuras das peças estruturais atendem ao projeto de Arquitetura em termos da sua relação com a forma (MACDONALD, 2001), com o espaço (SANDAKER, 2007), e com os demais sistemas prediais (CHING; ONOUYE; ZUBERBUHLER, 2010).

Ao se pensar a determinação da tipologia do sistema estrutural desconectada do projeto da forma arquitetônica, sendo este processo sendo denominado muitas vezes de lançamento estrutural, caracteriza assim um paradigma ultrapassado, talvez desde a década de 1960, uma época em que a tecnologia digital era restrita a alguns setores, como os militares, universidades e indústrias de tecnologia de ponta. Desde esta época até agora muito se desenvolveu tecnologicamente, desde tecnologias digitais de Modelagem Paramétrica (MP) e Fabricação Digital (FD) (KOLAREVIC, 2003; TEDESCHI, 2014; SOLLY et al., 2019), de materiais a serem empregados (STEWART, 2010; SOLLY et al., 2019), e até mesmo como se pensar o processo de projeto de edificações usando estas novas tecnologias (KOLAREVIC, 2009; OXMAN, 2010).

A construção arquitetônica contemporânea traz uma série de novas demandas urgentes de conhecimento sobre conteúdos e integração interdisciplinar ou transdisciplinar, cujo atendimento destas pode ser atingido com eficácia e eficiência usando ferramentas de simulação estrutural e o aparato tecnológico digital paramétrico e algorítmico. A MP estrutural tem capacidade de oferecer um dimensionamento automático das espessuras de peças estruturais (SILVA, 2017a; SILVA, 2017b; SILVA, 2018) e verificar o desempenho de vários sistemas estruturais que atendem a uma determinada demanda arquitetônica, escolhendo a melhor opção baseado em índices de desempenho (HOLZER, 2016).

Saramago (2011), há algum tempo já identificou e destacou - através de extensa pesquisa - que o ensino de Estruturas nas escolas de Arquitetura está deficitário. $O$ estudo foi realizado em diversas escolas de Arquitetura que conduziram uma missão de formar alunos com habilidades de concepção estrutural. Esta autora ainda apresentou algumas propostas de alguns professores consagrados de como deveria ser o conjunto de disciplinas de Estruturas numa graduação de Arquitetura.

Neste presente artigo, uma experiência de inclusão de tecnologias digitais no ensino de um conjunto de disciplinas obrigatórias de Estruturas em um curso de graduação em 
Arquitetura entre 2011 e 2019 será relatada. A experiência levou em consideração a problemática de ensino de estruturas para Arquitetura e a capacidade das tecnologias digitais atuais. Nas disciplinas conduzidas foram paulatinamente implementadas ferramentas computacionais para o desenvolvimento das atividades visando a sua produtividade e a precisão sobre a modelagem do desempenho mecânico, ambiental e financeiro das estruturas estudadas, sobretudo sobre a capacidade de vão da forma pretendida em projeto.

O fluxograma curricular deste curso de graduação tem cinco disciplinas obrigatórias de Estruturas: Física das Estruturas, oferecida no $3^{\circ}$ semestre; Estruturas I, oferecida no $4^{\circ}$ semestre; Estruturas II, oferecida no $6^{\circ}$ semestre; Estruturas III, oferecida no $8^{\circ}$ semestre; e Estruturas IV, oferecida no $9^{\circ}$ semestre.

Um marco importante para estas implementações da simulação estrutural nestas disciplinas foram as imprecisões observadas entre o processo de pré-dimensionamento e verificação dos Estados Limites das estruturas estudadas durante as atividades realizadas com os alunos. Usando os percentuais e ábacos de pré-dimensionamento fornecidos pela literatura, no começo deste período de análise, observou-se frequentemente um superdimensionamento ou um subdimensionamento das espessuras estruturais, gerando um retrabalho de modificação e atualização dos cálculos.

Foi verificado nesta experiência de ensino que estas técnicas de pré-dimensionamento por ábacos ou percentuais são muito imprecisas e isoladamente não ajudam muito na compreensão completa dos sistemas estruturais, a ponto de os próprios alunos fossem capazes de criar sistemas estruturais inovadores ou únicos. Além do fato de que não existem ábacos e percentuais para todas as situações de concepção estrutural. Sem verificar a viabilidade técnica do produto pelo próprio criador da forma, esta proposta irá ser verificada por um Engenheiro de Estruturas e, muitas vezes este terá que informar ao Projetista da Arquitetura que as espessuras pré-dimensionadas estão insuficientes, ou consome muito material.

Oxman (2010) se referiu a esse processo de trabalho tradicional entre Engenheiro de Estruturas e o Arquiteto como o processo forma-estrutura-material, concebendo primeiro a forma para depois, em colaboração com o engenheiro, projetar um sistema estrutural em um determinado material. Ela advoga que o novo estruturalismo traz a perspectiva de conceber a Estrutura e a Arquitetura seguindo uma lógica diferente: material-estrutura-forma; de maneira que a escolha do sistema estrutural e seu material estejam nas fases iniciais de concepção da forma arquitetônica. As tecnologias digitais podem auxiliar bastante nesse processo de projeto, já sendo encontrado alguns relatos na literatura de trabalhos que propõem o uso de simuladores digitais de estruturas nas fases preliminares do projeto arquitetônico (MORA; BEDARD; RIVARD, 2007; WONOTO, 2017).

Outros aspectos do projeto da forma podem ser considerados, sobretudo em relação a concepções de formas complexas ou de processos contemporâneos de fabricação, como a geometria e sua compatibilidade com o material e com o processo de fabricação (POTTMANN et al., 2015). Ou seja, o ensino de estruturas poderia discutir a fabricação e a montagem, o detalhamento e, na medida do possível, considerar restrições que estes processos trazem para o projeto do objeto arquitetônico.

Registros da literatura no tema e, considerando a experiencia profissional do autor no ensino de Estruturas em escolas de Arquitetura, revelam uma desatualização na discussão das temáticas aqui expostas. O cálculo manual e o desenho por esboços manuais, não caiu em desuso nos processos profissionais atuais de projeto de 
SILVA, F. T. da.

Experiências com ferramentas digitais no ensino de estruturas arquitetônicas

edificações, mas tomaram outro lugar. O cálculo de esforços e deslocamentos estruturais realizados manualmente só é viável quando o modelo estrutural é simplificado, por isso é muitas vezes impreciso. Quão mais complexas forem as formas - facilitadas por tecnologias de projeto e fabricação de objetos - mais imprecisos serão os cálculos manuais. Esta disponibilidade tecnológica atual facilitou formas otimizadas de aeronaves, automóveis e, atualmente edifícios, promovido pela disseminação do uso de sistemas CAD (Computer Aided Design), CAE (Computer Aided Engineering) e, mais recentemente, CAM (Computer Aided Manufacturing) (KOLAREVIC, 2003; SOLLY et al., 2019). Contudo, o cálculo estrutural manual e simplificado ainda serve para verificar ou validar o cálculo estrutural realizado pelo computador. No que concerne aos modelos físicos de desenvolvimento da intuição sobre a mecânica estrutural, estes também não caíram em desuso, sendo ainda muito importantes em uma primeira disciplina de uma estrutura curricular sobre ensino de estruturas. Contudo, modelos físicos que demonstram o comportamento ou a composição de sistemas estruturais não são suficientes para as discussões sobre o projeto completo de uma estrutura de um edifício.

\section{Metodologia de pesquisa}

Esta pesquisa abarca preceitos metodológicos das ciências naturais à medida que considera como procedimento de trabalho o modelo físico-matemático do funcionamento estrutural no uso de modelos preditivos, usado nas disciplinas para se obter resultados quantitativos do projeto de estruturas. Também estão inclusos os preceitos da ciência do projeto (Design Science) uma vez que são investigadas maneiras de alcançar melhores resultados no ensino do projeto de estruturas com uma abordagem com foco na resolução de problemas.

Em termos de método científico esta pesquisa utiliza o método dedutivo no uso do equacionamento físico-matemático na modelagem de sistemas e implementações nas ferramentas digitais, enquanto usa também o método indutivo na aposta de que o uso de simuladores de estruturas pode preencher o vazio que dificulta o Arquiteto acessar com precisão a habilidade de projetar as estruturas. Por outro lado, o processo de implementação das ferramentas nas diversas disciplinas de estruturas se configura como uma atividade de Pesquisa-Ação, propondo resolver o problema de eficácia e eficiência no processo de projeto entre Arquitetos e Engenheiros de Estruturas.

Ao se verificar, no início do período de ensino aqui analisado, que as técnicas de prédimensionamento por percentuais ou ábacos geravam inúmeros retrabalhos, além de não contemplar todas as complexidades possíveis das proposições arquitetônicas concebidas nas disciplinas de Projeto de Arquitetura, lançou-se como hipótese o uso de ferramentas digitais nesta estrutura curricular usada nesta pesquisa como objeto de estudo. De certo, os alunos de Arquitetura demonstram no geral grande facilidade em lidar com processos de modelagem computacional, o que se tomou como hipótese para que isso mitigasse a delimitação curricular em termos de cálculo diferencial que a graduação em Arquitetura tem em comparação com a graduação em Engenharia Civil.

Por sua vez, os conceitos da Pesquisa da Ciência do Projeto (Design Science Research) (DRESCH; LACERDA; ANTUNES JÚNIOR, 2015) também são incorporados por esta pesquisa, trazendo o conceito do artefato tanto na incorporação de ferramentas digitais no ensino de estruturas para arquitetos, quanto no estudo e prática da concepção estrutural nas fases iniciais do projeto de Arquitetura. 
SILVA, F. T. da.

Experiências com ferramentas digitais no ensino de estruturas arquitetônicas

\section{Estrutura curricular e recursos utilizados}

O objeto de estudo desta pesquisa é a implementação de ferramentas digitais, para o ensino de concepção e projeto de estruturas arquitetônicas, contextualizado e experimentado sobre uma estrutura curricular de disciplinas obrigatórias de estruturas em um curso de Arquitetura. As ementas destas disciplinas possuem definidas desde o funcionamento mecânico estrutural até o projeto e detalhamento da estrutura para a Arquitetura, sendo aqui descritas para clarificar o contexto de experimentação sobre o ensino. Todas as atividades de concepção estrutural foram realizadas sobre proposições de projeto desenvolvidas previamente ou concomitantemente em alguma disciplina de Projeto Arquitetônico realizado pelos próprios estudantes.

No Quadro 1 estão organizadas as disciplinas, oficinas e o ferramental computacional das quatro fases de implementação nesta experiência durante este período em análise. A fase 1 se realizou em 2011 e 2012, a fase 2 desde 2013 a 2016, a fase 3 em 2017 (no período de pós-doutorado do autor) e a fase 4, em 2018 e 2019.

\begin{tabular}{|c|c|c|}
\hline Disciplina / Oficina & Conteúdos & Recursos utilizados (fase) \\
\hline Física das Estruturas & Mecânica Estrutural e Resistencia dos Materiais & $\begin{array}{l}\text { Ftool (fase1), Robot (fases } 2 \text { e 4), Karamba } \\
\text { (fase 4) }\end{array}$ \\
\hline Estruturas I & Concepção e pré-dimensionamento estrutural & Excell e Robot (2 e 4) \\
\hline Estruturas II & Projeto e detalhamento de estruturas de concreto & $\begin{array}{l}\text { Ftool (1), Excell e Robot (2 e 4), Karamba } \\
\text { (4) }\end{array}$ \\
\hline Estruturas III & Projeto e detalhamento de estruturas de aço & $\begin{array}{l}\text { Ftool (1), Excell e Robot ( } 2 \text { e 4), Karamba } \\
\qquad(4)\end{array}$ \\
\hline Estruturas IV & Projeto e detalhamento de estruturas de madeira & $\begin{array}{l}\text { Ftool (1), Excell e Robot (2 e 4), Karamba } \\
\qquad(4)\end{array}$ \\
\hline $\begin{array}{l}\text { Informática Aplicada ao } \\
\text { Projeto Estrutural }\end{array}$ & BIM, Dimensionamento automático e form-finding & Revit e Robot (2 e 4), Karamba (4) \\
\hline $\begin{array}{l}\text { Projeto Paramétrico de } \\
\text { Estruturas Arq. }\end{array}$ & MP de Estruturas e form-finding & Karamba (3) e Millipede (3) \\
\hline $\begin{array}{l}\text { Oficinas de Pavilhões de } \\
\text { Pesquisa }\end{array}$ & MP, FD e Montagem de Pavilhões & Karamba (3 e 4) \\
\hline
\end{tabular}

Fonte: $\mathrm{O}$ autor

Na fase 1 de implementação destes recursos didáticos nas disciplinas foram usados apenas o programa de simulação estrutural Ftool e cálculos manuais de prédimensionamento e dimensionamento. Nesta época não se tinha conhecimento de um simulador computacional de estruturas além do Ftool, em que também tivesse o uso acadêmico disponível para os alunos. O Ftool é um programa gratuito de cálculo de modelos bidimensionais de barras estruturais a partir de métodos analíticos, gerando diagramas de esforços e de configurações deformadas. O Programa tem origem brasileira (BRANCHIER, 2017), lançado em 1998, com última versão em 2018 e com poucas alterações até o momento atual. Além da impossibilidade de se considerar o peso próprio automaticamente ou até mesmo a sistemática de combinações de carga, o programa só realiza simulações bidimensionais, fazendo assim com que o Ftool não seja a escolha mais adequada para ser utilizado como simulador estrutural para uso profissional em projeto de estruturas nos dias atuais.

$\mathrm{Na}$ fase 2 foram realizadas a implementação do Robot em substituição do Ftool; implementação das planilhas eletrônicas automáticas com formulações analíticas de subsistemas estruturais para pré-dimensionamento de pórticos; implementação das planilhas eletrônicas automáticas para dimensionamento de armaduras do concreto armado, verificação de seções em aço e madeira, como também o dimensionamento das ligações entre as peças estruturais. 
O Robot é um simulador de estruturas baseado no método dos elementos finitos com a capacidade de modelar barras, superfícies e volumes. Originalmente foi criado por Andrew Niznik como parte de sua tese de Doutorado em INSA Toulouse em 1983, se popularizou na França e Europa nos anos 1990 e 2000, posteriormente foi adquirido pela Autodesk e, em meados de 2009 lançado pela primeira vez por esta software-house (MARSH, 2015). Em 2013 esta ferramenta começou a ser utilizada como base para todas estas disciplinas aqui descritas nesta experiencia e pesquisa sobre o ensino de estruturas: capacitação na primeira disciplina como pano de fundo para o estudo de mecânica e da estabilidade das estruturas, além da verificação das estruturas de acordo com os Estados Limites. O uso foi contínuo como ferramenta para realização de todas as atividades de todas as disciplinas aqui descritas, dando suporte às atividades de detalhamento de armaduras e conexões segundo as normas de projeto estrutural.

Devido à imprecisão dos percentuais de pré-dimensionamento disponíveis na literatura, foram desenvolvidas expressões de pré-dimensionamento a partir de formulações analíticas de modelos estruturais, considerando como parâmetros: as dimensões globais da estrutura, a seção transversal das peças, a resistência do material e o nível de cargas e a composição do sistema estrutural por completo. Cada subsistema estrutural foi formulado individualmente, considerando o caminho natural das forças para conectá-los entre si de modo a considerar a influência entre estes. Foram realizadas formulações para pórticos de multi-pavimentos em concreto armado (BRITO; SILVA, 2015; SILVA, 2017b) e em perfis laminados de aço (SANTOS; SILVA, 2016). Também foram desenvolvidas formulações para estruturas de coberturas em aço e de madeira, assim como rampas e escadas. Apesar de mais precisas que os percentuais, estas formulações analíticas foram aplicadas em casos específicos e completamente modulares, não se adequando perfeitamente a casos muito específicos.

No entanto, as expressões desenvolvidas não são práticas se utilizadas manualmente e, portanto, foram implementadas em planilhas eletrônicas automatizadas para o uso dos alunos nas atividades de concepção. Estas planilhas foram usadas nas atividades da disciplina Estruturas I, II, III e IV. As células destas planilhas foram coloridas para indicar quais são as células que são de variáveis de dados de entrada e quais são as células com os resultados dos cálculos automáticos de pré-dimensionamento e também as células que não são de dados de entrada foram travadas para que os alunos não pudessem alterar as fórmulas ou fazer um uso indevido. Um exemplo de planilha de prédimensionamento de sistema de piso com vigas em perfis $W$ e laje de concreto armado é exibido pelo Quadro 2, no qual em cinza estão as células em que os alunos informam os dados de entrada e em roxo estão as células com os resultados processados automaticamente, obtendo os resultados através das formulações analíticas desenvolvidas.

Foram construídas planilhas de pré-dimensionamento considerando lajes maciças, treliçadas pré-fabricadas, nervuradas com formas em cubetas plásticas, com funcionamento unidirecional e bidirecional. Para o caso de sistemas de piso com vigas em aço, foram consideradas lajes maciças, treliçadas pré-fabricadas e steel-deck. $\mathrm{Na}$ escolha dos perfis de vigas em aço, foi implementado na célula de escolha da lista de perfis catalogada o recurso drop-down, para que o aluno escolhesse dentro da oferta de perfis padronizada, como pode ser observado no exemplo exibido pelo Quadro 2.

A partir de uma definição de uma espessura da laje, a planilha fornece um vão máximo modular para a laje em um contexto de uma unidade básica, definindo automaticamente assim os vãos das vigas que a apoia. Em um segundo passo, escolhese a base da seção retangular, quando a viga é em concreto armado, verificando a altura mínima para que esta atenda aos requisitos para o vão definido. No caso de vigas em 
SILVA, F. T. da.

Experiências com ferramentas digitais no ensino de estruturas arquitetônicas

aço, escolhe-se o perfil na lista de perfis, verificando a demanda de perfil pelos parâmetros geométricos da seção, verificando se estes são atendidos pelos parâmetros do perfil escolhido.

Quadro 2 - Exemplo de uma das planilhas de pré-dimensionamento automático de sistemas de pisos com as expressões analíticas desenvolvidas

\begin{tabular}{|c|c|c|c|c|c|c|c|c|}
\hline \multicolumn{9}{|c|}{ Dados de entrada da laje maciça unidirecional } \\
\hline $\mathrm{d}(\mathrm{cm})$ & $\begin{array}{c}\text { fck } \\
(\mathrm{MPa})\end{array}$ & $\begin{array}{c}q p p \\
\left(\mathrm{KN} / \mathrm{m}^{2}\right)\end{array}$ & \multicolumn{2}{|c|}{ qrev $\left(\mathrm{KN} / \mathrm{m}^{2}\right)$} & \multicolumn{2}{|c|}{ qvar $\left(\mathrm{KN} / \mathrm{m}^{2}\right)$} & \multicolumn{2}{|c|}{ qlaje $\left(\mathrm{KN} / \mathrm{m}^{2}\right)$} \\
\hline 13 & 30 & 3.25 & \multicolumn{2}{|c|}{1.00} & \multicolumn{2}{|c|}{3.00} & \multicolumn{2}{|r|}{7.25} \\
\hline \multicolumn{9}{|c|}{ Dados de saída da laje - Vão máximo } \\
\hline$\underset{(m)}{\text { L_mf }}$ & $\begin{array}{l}\text { L_ec } \\
(\mathrm{m})\end{array}$ & $\underset{(\mathrm{m})}{\text { L_des1 }}$ & $\begin{array}{c}\text { L_des2 } \\
(\mathrm{m})\end{array}$ & \multicolumn{2}{|c|}{ L_máximo (m) } & \multicolumn{2}{|c|}{ L_adotado (m) } & $d / L$ \\
\hline 7.14 & 7.44 & 4.51 & 6.51 & \multicolumn{2}{|c|}{4.51} & \multicolumn{2}{|c|}{4.25} & $3.1 \%$ \\
\hline \multicolumn{9}{|c|}{ Dados de entrada das vigas secundárias } \\
\hline $\begin{array}{c}\text { qalv } \\
(\mathrm{KN} / \mathrm{m})\end{array}$ & $\begin{array}{c}\text { fy } \\
(\mathrm{MPa})\end{array}$ & $\mathrm{n}$ & \multicolumn{2}{|c|}{ Perfil } & $\begin{array}{c}\text { qpp_sec } \\
(\mathrm{KN} / \mathrm{m})\end{array}$ & Rlaje (KN/m) & $\begin{array}{c}\text { L_sec } \\
(\mathrm{m})\end{array}$ & h_perfil (mm) \\
\hline 0.00 & 345 & 2 & \multicolumn{2}{|c|}{ W $530 \times 82,0$} & 0.82 & 15.41 & 8.5 & 528 \\
\hline \multicolumn{9}{|c|}{ Dados de saída das vigas secundárias } \\
\hline \multirow{2}{*}{$\begin{array}{c}\text { demanda } \\
\text { de perfil }\end{array}$} & $\begin{array}{c}\text { Wx_min } \\
\left(\mathrm{cm}^{3}\right)\end{array}$ & $\begin{array}{c}\text { As_min } \\
\left(\mathrm{cm}^{2}\right)\end{array}$ & $\begin{array}{l}\text { Ix_min } \\
(\mathrm{cm} 4)\end{array}$ & \multirow{2}{*}{$\begin{array}{c}\text { capacidade } \\
\text { do perfil } \\
\text { escolhido }\end{array}$} & $W x\left(\mathrm{~cm}^{3}\right)$ & As $\left(\mathrm{cm}^{2}\right)$ & $\begin{array}{c}\mathrm{Ix} \\
(\mathrm{cm} 4)\end{array}$ & hs/Ls \\
\hline & 1159.3 & 5.3 & 43143.8 & & 1801.8 & 104.5 & 47569.0 & $6.2 \%$ \\
\hline \multicolumn{9}{|c|}{ Dados de entrada das vigas principais ( $2 \mathrm{M})$} \\
\hline $\begin{array}{c}\text { qalv } \\
(\mathrm{KN} / \mathrm{m})\end{array}$ & $\begin{array}{c}\text { fy } \\
(\mathrm{MPa})\end{array}$ & $\mathrm{n}$ & \multicolumn{2}{|c|}{ Perfil } & $\begin{array}{l}\text { qpp_pri } \\
(\mathrm{KN} / \mathrm{m})\end{array}$ & qpri (KN/m) & $\begin{array}{c}\text { L_pri } \\
(\mathrm{m})\end{array}$ & h_perfil (mm) \\
\hline 0.00 & 345 & 2 & \multicolumn{2}{|c|}{$W 610 \times 101,0$} & 1.01 & 51.62 & 8.50 & 603 \\
\hline \multicolumn{9}{|c|}{ Dados de saída das vigas principais } \\
\hline \multirow{2}{*}{$\begin{array}{c}\text { demanda } \\
\text { de perfil }\end{array}$} & $\begin{array}{c}\text { Wx_min } \\
\left(\mathrm{cm}^{3}\right)\end{array}$ & $\begin{array}{c}\text { As_min } \\
\left(\mathrm{cm}^{2}\right)\end{array}$ & $\begin{array}{l}\text { Ix_min } \\
(\mathrm{cm} 4)\end{array}$ & \multirow{2}{*}{$\begin{array}{c}\text { capacidade } \\
\text { do perfil } \\
\text { escolhido }\end{array}$} & $W x\left(\mathrm{~cm}^{3}\right)$ & As $\left(\mathrm{cm}^{2}\right)$ & $\begin{array}{c}\mathrm{Ix} \\
(\mathrm{cm} 4)\end{array}$ & $h p / L p$ \\
\hline & 1891.9 & 8.9 & 68794.1 & & 2554.0 & 130.3 & 77003.0 & $7.1 \%$ \\
\hline
\end{tabular}

Nota: Esta planilha e outras planilhas de pré-dimensionamento estão disponíveis https://doi.org/10.5281/zenodo.5213915. Fonte: Tavares (2021).

Nestas planilhas de pré-dimensionamento também é verificado qual seria o percentual de pré-dimensionamento correspondente, podendo-se assim fazer uma comparação entre as propostas de percentuais sugeridas pela literatura. Frequentemente se observa que os percentuais obtidos pelas planilhas diferiam das propostas da literatura, tanto para concreto armado quanto para aço ou madeira.

Nas disciplinas Estruturas II, III e IV foram também utilizadas planilhas eletrônicas automáticas para dimensionamento e detalhamento das armaduras e verificações de peças em aço ou madeira e também a verificação suas de ligações estruturais a partir das expressões que podem ser obtidas na literatura do tema. Estas expressões matemáticas para dimensionamento e verificação dos detalhamentos são relacionadas às normas brasileiras atuais de projeto e detalhamento de estruturas.

No Quadro 3 é exibida uma destas planilhas de dimensionamento e detalhamento das peças estruturais usadas no desenvolvimento dos trabalhos com os estudantes, especificamente neste caso, a planilha de dimensionamento, detalhamento e verificação à fissuração de vigas em concreto armado. Após a modelagem no Robot, os alunos puderam extrair os esforços críticos dos elementos projetados e usar como dado de entrada nestas planilhas automáticas de dimensionamento e detalhamento de estruturas em concreto armado, aço e madeira. 
SILVA, F. T. da.

Experiências com ferramentas digitais no ensino de estruturas arquitetônicas

Quadro 3 - Exemplo de planilha automática de dimensionamento, detalhamento e verificação de vigas em concreto armado

\begin{tabular}{|c|c|c|c|c|c|c|c|c|}
\hline \multicolumn{9}{|c|}{ Dimensionamento da armadura longitudinal das vigas em concreto armado - Dados de entrada } \\
\hline \multicolumn{2}{|c|}{ bw $(m)$} & \multicolumn{2}{|r|}{$h(m)$} & $\begin{array}{l}\text { cobrimento } \\
\text { (m) }\end{array}$ & $d(m)$ & Md (KN.m) & fck (MPa) & fy (MPa) \\
\hline \multicolumn{2}{|c|}{0.20} & \multicolumn{2}{|r|}{0.45} & 0.035 & 0.415 & 21.69 & 30 & 500 \\
\hline \multicolumn{9}{|c|}{ Dados de saída e verificações da seção em concreto armado } \\
\hline \multicolumn{2}{|c|}{$x(m)$} & \multicolumn{2}{|r|}{$\mathrm{x} / \mathrm{d}$} & \multicolumn{2}{|c|}{$\rho \_\min$} & As_min $\left(\mathrm{cm}^{2}\right)$ & As_nec $\left(\mathrm{cm}^{2}\right)$ & As_max $\left(\mathrm{cm}^{2}\right)$ \\
\hline \multicolumn{2}{|c|}{0.018} & \multicolumn{2}{|r|}{0.04} & \multicolumn{2}{|c|}{0.0015} & 1.35 & 1.22 & 36.00 \\
\hline \multicolumn{9}{|c|}{ Detalhamento das armaduras e verificação à fissuração } \\
\hline \multirow{2}{*}{\multicolumn{3}{|c|}{ escolha da bitola }} & \multicolumn{3}{|c|}{ ancoragem } & \multicolumn{3}{|c|}{ Controle de fissuras } \\
\hline & & & reta & \multicolumn{2}{|c|}{ gancho } & & & \\
\hline $\begin{array}{c}\Phi \\
(\mathrm{mm})\end{array}$ & $\mathrm{n}$ & $\begin{array}{c}\mathrm{e} \\
(\mathrm{cm})\end{array}$ & $\begin{array}{l}\text { Lb_nec } \\
(\mathrm{cm})\end{array}$ & $\begin{array}{l}\text { Lb_nec } \\
(\mathrm{cm})\end{array}$ & $\begin{array}{l}\text { comp gancho } \\
(\mathrm{cm})\end{array}$ & $\begin{array}{c}\text { tensão na barra } \\
\text { (MPa) }\end{array}$ & $\begin{array}{l}\text { tensão limite } \\
(\mathrm{MPa})\end{array}$ & e_max $(\mathrm{cm})$ \\
\hline 8 & 3 & 4.6 & 34.4 & 24.1 & 7 & 252.1 & 280 & 15 \\
\hline 10 & 2 & 9.7 & 41.3 & 28.9 & 8 & 242.0 & 280 & 15 \\
\hline 12.5 & 2 & 9.2 & 33.0 & 23.1 & 10 & 154.9 & 160 & 30 \\
\hline
\end{tabular}

Nota: Esta planilha e outras planilhas de pré-dimensionamento estão disponíveis https://doi.org/10.5281/zenodo.5213915. Fonte: Tavares (2021)

A fase 3 desta experiência de ensino foi durante o período de pós-doutorado do autor, onde foram realizadas atividades de oficinas de montagens de pavilhões estruturais, a oferta de uma disciplina eletiva sobre projeto paramétrico de estruturas arquitetônicas e orientações sobre concepção estrutural em uma disciplina de Projeto Arquitetônico de edificações verticais (Verticalidade). Nesta experiência de pós-doutorado foram produzidos pavilhões em escala 1:1 e também maquetes na escala 1:3, utilizando formfinding com MP e FD. A disciplina eletiva ofertada abordou a introdução ao Grasshopper $(\mathrm{GH})$, a modelagem estrutural utilizando o Karamba e a otimização topológica utilizando o Millipede. Foram fornecidos aos alunos um código do $\mathrm{GH}$ com a capacidade de verificar automaticamente estruturas de concreto armado ou de aço ao se utilizar o Karamba em proposições projetuais.

O Karamba (PREISINGER; HEIMRATH, 2014) é um add-on do GH, que por sua vez é um plug-in do Rhinoceros (RH). O RH é um software CAD que atualmente vem sendo utilizado bastante para o projeto de objetos arquitetônicos e cidades, tendo o $\mathrm{GH}$ como um plugin de programação algorítmica para produzir modelos digitais a partir de algoritmos generativos. O Karamba entra neste conjunto de ferramentas computacionais com um simulador estrutural utilizando o método dos elementos finitos, modelando a física estrutural sobre a geometria modelada parametricamente.

Outra ferramenta de modelagem estrutural disponível na combinação RH-GH é o addon Millipede (MICHALATOS, 2014; BIALKOWSKI,2017), disponibilizando a otimização topológica e outras capacidades de modelagem estrutural. Foi explorado o recurso de otimização topológica na disciplina eletiva oferecida nesta fase 3. A otimização topológica é um tipo de modelagem estrutural que determina a forma da estrutura a partir de um domínio definido, definindo também quais as suas regiões de cargas atuantes e as regiões de restrição de deslocamento, os apoios. Com isso o algoritmo determina uma forma tridimensional, distribuindo o material de forma otimizada entre a aplicação das cargas e os apoios, considerando o caminho das forças e a resistência do material.

A fase 4 foi o período após a realização da experiência do pós-doutorado do autor, considerando a inserção de form-finding com o Karamba nas disciplinas Estruturas II, III e IV para geração de formas livres (free-forms), concebendo estruturas funiculares em casca de concreto e diagrids em aço e em madeira, respectivamente. Foi introduzida 
também a possibilidade de se utilizar a concepção estrutural com pré-dimensionamento automático com códigos do GH em conjunto com componentes do Karamba. Também foi implementado nos dois anos desta fase algumas oficinas de projeto-fabricaçãomontagem de pavilhões como atividade de extensão, com o objetivo de investigar sistemas funiculares e os processos de concepção e materialização da forma, assim como promover uma atividade integrada e multidisciplinar de projeto de um objeto arquitetônico.

A estratégia básica ao montar e estruturar as disciplinas de estruturas deste curso de graduação em Arquitetura foi considerar na primeira disciplina a promoção da proficiência em Simulação Estrutural dos alunos em conjunto com os conteúdos de Mecânica Estrutural e noções básicas dos Estados Limites, na disciplina Física das Estruturas. A partir da capacitação dos alunos no uso de simuladores estruturais, estes puderam por conta própria verificar a condição de aceitabilidade da Estrutura de seus projetos propostos quanto aos Estados Limites e também quanto ao nível de consumo de material.

Na disciplina seguinte, chamada Estruturas I, foram exploradas questões de concepção Estrutural aliada a Arquitetura, compondo proposições com consciência sobre a sua viabilidade técnica e financeira da composição estrutural, adicionalmente à relação deste sistema com os demais sistemas prediais e o próprio espaço arquitetônico. Foram utilizadas nessa disciplina tanto as planilhas de pré-dimensionamento automáticas (Excel) quanto o analisador estrutural (inicialmente o Ftool e posteriormente o Robot).

Nas disciplinas Estruturas II, III e IV foram exploradas nas atividades aspectos de concepção, projeto e detalhamento de estruturas de concreto armado, aço e madeira, respectivamente. Estas disciplinas eram divididas em três unidades, sendo a primeira com fundamentos e particularidades destes materiais estruturais; a segunda o projeto de pórticos e; a terceira unidade o projeto de estrutura complexa em casca de concreto, diagrids de aço ou de madeira.

As atividades projetivas destas disciplinas assumiam um programa arquitetônico desenvolvido pelos alunos nas disciplinas de Oficina de Projeto Arquitetônico, conduzida por professores arquitetos. De modo que algumas vezes as definições do espaço arquitetônico já tinham sido determinadas, orientava-se os alunos a considerar que a arquitetura ainda estava em fase preliminar e o espaço poderia ser ajustado de modo a melhor encaixar uma ou mais opções de configuração do sistema estrutural de acordo com o programa de necessidades da Arquitetura. Por outro lado, quando o aluno estava desenvolvendo um projeto arquitetônico na disciplina de Projeto Arquitetônico concomitante com a disciplina de Estruturas este tinha a oportunidade de definir a estrutura nas fases preliminares do desenvolvimento da proposta arquitetônica.

\section{Resultados}

Serão mostrados aqui nesta seção uma seleção de alguns dos trabalhos dos alunos envolvidos neste processo, evidenciando os ganhos obtidos em produções de concepção consistentes. Faz-se necessário observar os ganhos de qualidade de concepção ao se implementar o Robot como simulador estrutural tridimensional a partir da fase 2, além das planilhas automáticas de pré-dimensionamento e dimensionamento estrutural. A partir da fase 2 observou-se uma diminuição de reprovações, trancamentos e um leve aumento na média das turmas.

Adicionalmente, percebe-se também que há um interesse geral das turmas de Arquitetura em aprender mais sobre o funcionamento estrutural, sendo verificada uma produção extremamente profissional como podemos observar nas Figuras 1 a 11. 
SILVA, F. T. da.

Experiências com ferramentas digitais no ensino de estruturas arquitetônicas

Na Figura 1 se observa a concepção estrutural e arquitetônica de um teatro contendo o auditório principal e diversos outros espaços compondo o programa de necessidades. O sistema concebido consiste em uma estrutura de arcos que apoiam placas maciças em concreto, tendo espaços com funções distintas compartimentados com o uso do sistema de pórticos também em concreto armado. Foram considerados ábacos de prédimensionamento de arcos e vigas de alma cheia e lajes, tanto para as lajes em si quanto para a casca entre os arcos.

Figura 1 - Projeto de um teatro em concreto armado realizado em equipe na disciplina Estruturas I, Fase 1.

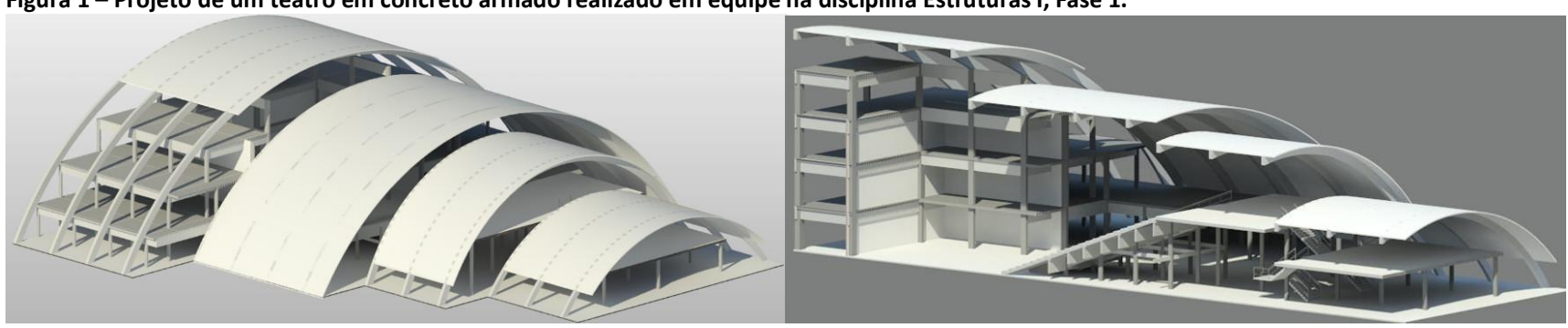

Nota: vista geral do teatro (à esquerda) e do Modelo 3D secionado (à direita). Fonte: fornecido e autorizado pelos alunos da equipe do trabalho.

Ainda na Figura 1 é possível observar uma excelente sofisticação na representação gráfica gerada a partir de ferramenta BIM, contudo a concepção estrutural e prédimensionamento se limitou a considerar ábacos e percentuais. Neste caso, algumas inconsistências puderam ficar evidentes: vãos de viga e laje com proporções em relação às espessuras em valores duvidosos e quanto à sua adequação aos Estados Limites, além da relação do funcionamento da vedação em laje arqueada, que por sua vez tem um funcionamento à flexo-compressão ao invés de flexão simples. Nesta fase estava sendo usado o Ftool que não possui a capacidade de simular cascas ou laje, limitando muito o desenvolvimento fidedigno deste trabalho.

Na Figura 2 está ilustrada a concepção de um templo religioso, contendo tirantes, vãos relativamente grandes e utilizou o Ftool para verificar o comportamento de alguns pórticos desta estrutura concebida.

Um problema importante no uso de ábacos e percentuais para o pré-dimensionamento combinado com um simulador estrutural muito simples como o Ftool é que ao se obter a resposta da insuficiência das espessuras das peças estruturais em relação aos vãos e cargas, necessita-se modificar o sistema, inicialmente alterando a espessura do elemento para que ele atenda aos Estados Limites. Contudo, o Ftool não considera o peso próprio das peças automaticamente a partir da definição das suas seções transversais, sendo o peso próprio computado no a partir de cargas lineares equivalentes. Ou seja, se há a necessidade de alteração das espessuras, a carga a ser aplicada representativa do peso próprio precisa ser recalculada manualmente para se obter uma resposta atualizada frente à mudança projetual. Com o uso do Robot, o ganho em produtividade foi muito maior devido à sua característica de modelagem tridimensional e de qualquer tipo de forma e geometria, além do cálculo automático do peso próprio das peças estruturais 
SILVA, F. T. da.

Experiências com ferramentas digitais no ensino de estruturas arquitetônicas

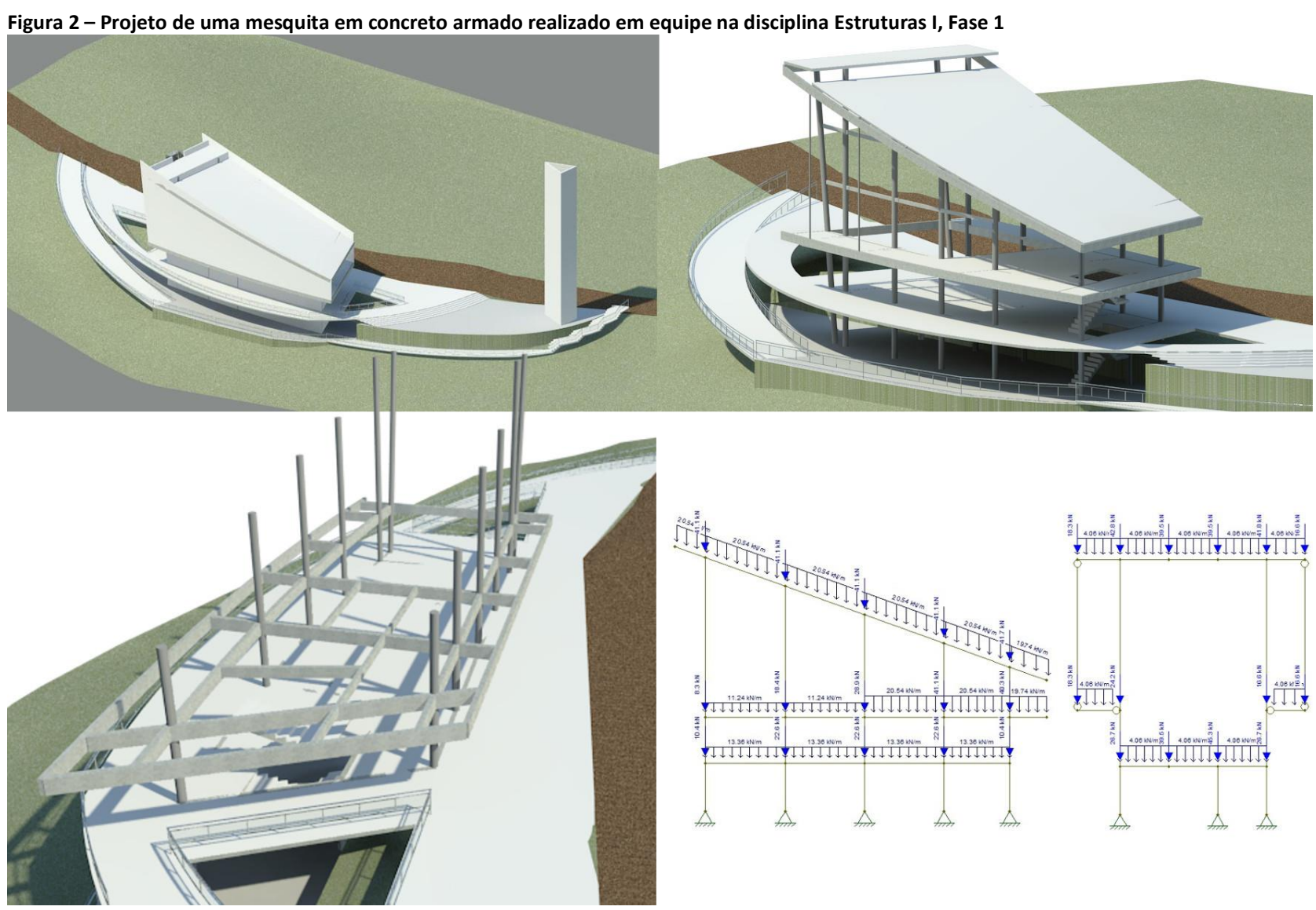

Nota: vista geral da mesquita (à esquerda acima), vista geral da estrutura (à direita acima), Vista com parte da estrutura mostrando os pilares e vãos internos com vigamentos (à esquerda abaixo) e modelos 2D estruturais deste projeto (à direita abaixo). Fonte: fornecido e autorizado pelos alunos da equipe do trabalho.

Na Figura 3 é ilustrado outro projeto concebido ainda na Fase 1 desta pesquisa, consistindo de um templo religioso com planta circular. A simplificação neste caso, para se poder modelar a estrutura no Ftool foi ainda maior, sendo possível apenas modelar os pórticos radiais, com peças retilíneas, não sendo possível modelar os pórticos formados ao longo das circunferências da planta, uma vez que o simulador usado não tem a capacidade de modelar vigas curvas como neste caso.

Na Figura 4 está ilustrado um exemplo da Fase 2 desta pesquisa, em que foi utilizado o Robot nas atividades de concepção e verificação estrutural com os alunos. Neste projeto de uma midiateca em estrutura metálica foi utilizada uma base de dados de perfis laminados em aço, trazendo coerência com a disponibilidade de material pré-fabricado oferecendo facilidade também na modificação de perfis quando se fez necessário. Observa-se ainda que o projeto e modelagem é de uma estrutura mista, considerando a infraestrutura em concreto armado e a modelagem de lajes, tudo em um único modelo que contempla as inter-relações de subsistemas estruturais e materiais.

Como esperado, os estudantes não demonstraram dificuldades no uso operacional do Robot, pelo contrário, a possibilidade de não ter limitações de concepção, interoperabilidade com o Revit, e consideração automática do peso próprio dos elementos na composição das cargas foram elementos motivadores na adoção da ferramenta de simulação. 
SILVA, F. T. da.

Experiências com ferramentas digitais no ensino de estruturas arquitetônicas

Figura 3 - Projeto de igreja em concreto armado - Estruturas II, Fase 1

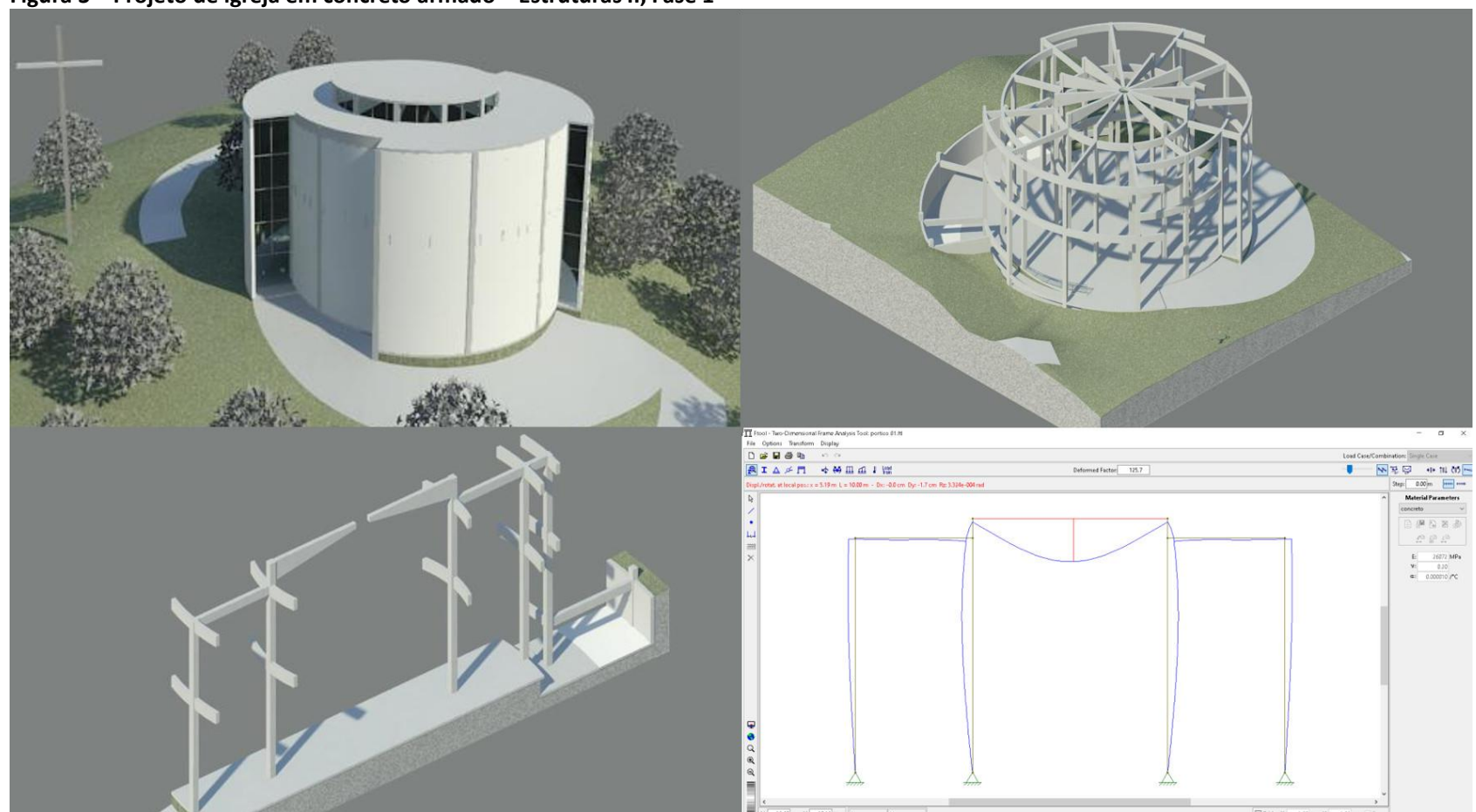

Nota: vista geral da igreja (à esquerda acima), vista geral da estrutura (à direita acima), Vista com parte da estrutura mostrando um dos pórticos da estrutura (à esquerda abaixo) e modelo 2D estrutural deste pórtico (à direita abaixo). Fonte: fornecido e autorizado pelos alunos da equipe do trabalho.

Figura 4 - Projeto de midiateca em perfis laminados de aço - Estruturas III, Fase 2
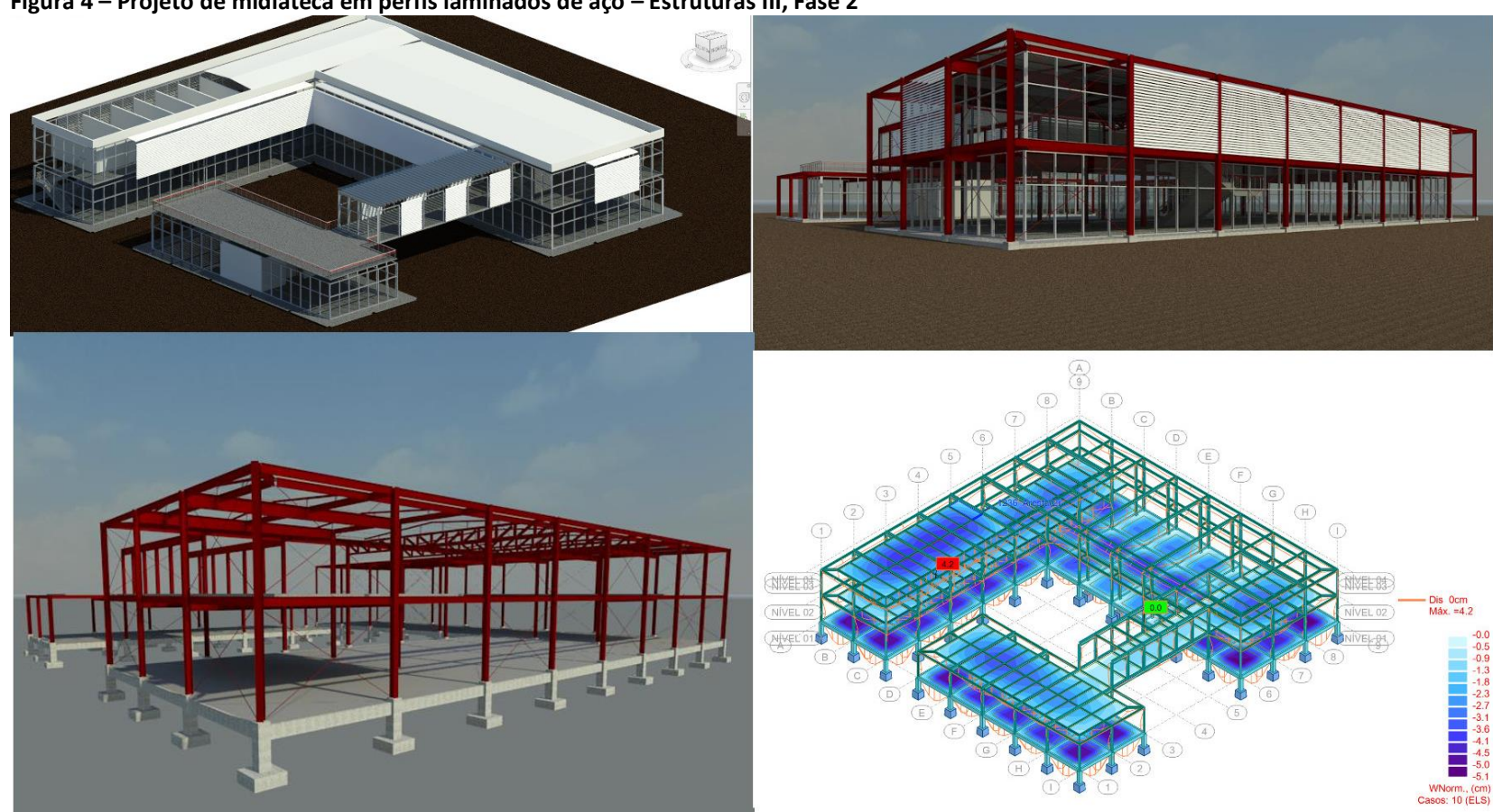

Nota: vista geral da Midiateca (à esquerda acima), vista geral da estrutura (à direita acima), Vista com parte da estrutura mostrando a estrutura metálica e a infraestrutura em concreto armado (à esquerda abaixo) e modelo 2D estrutural deste pórtico (à direita abaixo). Fonte: fornecido e autorizado pelos alunos da equipe do trabalho.

A Figura 5 ilustra um projeto de um mirante com barras rústicas de eucalipto, numa composição arrojada e verificada e detalhada de acordo com a norma brasileira de projeto de estruturas de madeira. $O$ resultado final com peças esbeltas, porém dentro do permitido, e uma composição distante de uma compreensão óbvia de pórticos resultou numa satisfatória combinação de arquitetura e estrutura. 
SILVA, F. T. da.

Experiências com ferramentas digitais no ensino de estruturas arquitetônicas
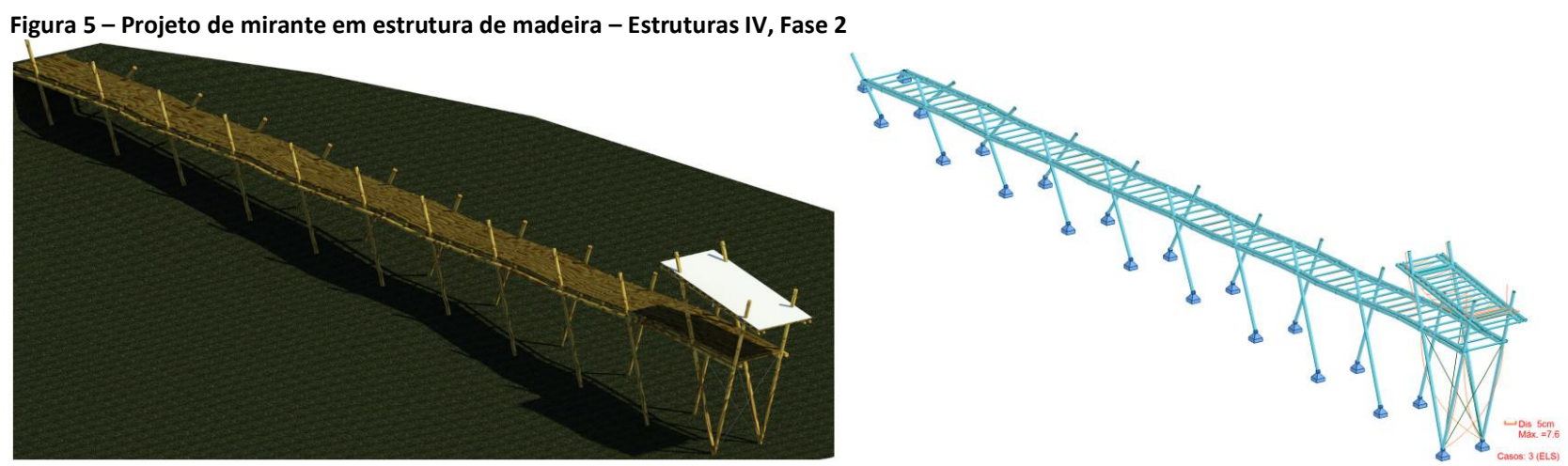

Nota: vista geral do mirante (à esquerda), modelo da estrutura em madeira (à direita). Fonte: fornecido e autorizado pelos alunos da equipe do trabalho.

Na Figura 6 estão ilustradas experimentações em disciplina eletiva oferecida durante a experiência de pós-doutorado do autor, contando também com ferramentas paramétricas para verificar o comportamento de casos clássicos da arquitetura, de técnicas não-convencionais como a otimização topológica e também proposições complexas como o arranjo completo e parametrizado de uma estação de trem, otimizando o consumo de material estrutural na modificação concomitante de vãos e espessuras enquanto se definia o projeto do espaço arquitetônico.

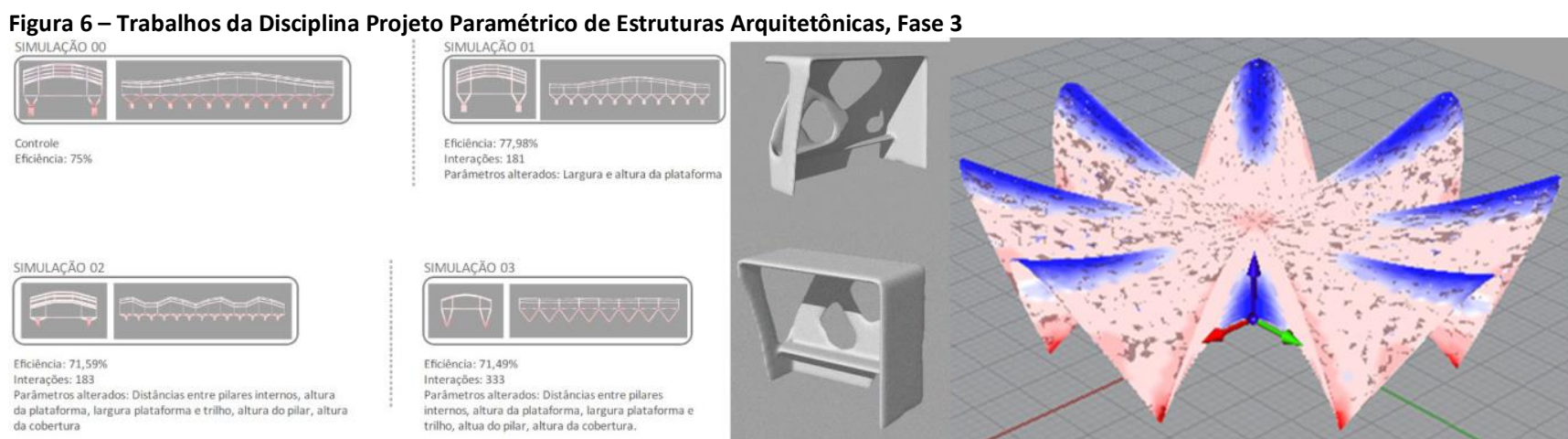

Nota: Opções de Projeto de estação de trem (à esquerda), parada de ônibus (ao centro), estudo sobre o projeto Los Manantiales (à direita). Fonte: fornecido e autorizado pelos alunos da equipe do trabalho.

Além desta disciplina eletiva, o autor também realizou experimentações com a fabricação digital e montagem pavilhões. Esta experiência se demonstrou extremamente frutífera no que diz respeito a conteúdos não contemplados diretamente e explicitamente nas disciplinas obrigatórias de concepção e projeto estrutural. Algumas produções destas oficinas de fabricação e montagem de pavilhões estão ilustradas em fotografias dos modelos fabricados, visualizadas nas Figuras 7 e 8.

Em continuidade, a denominada Fase 4 consiste na manutenção de uso do Robot como recurso de projeto nas atividades das disciplinas obrigatórias de concepção e projeto estrutural. Nas Figuras 9, 10 e 11 são ilustrados resultados de concepção e projeto estrutural dos alunos com um grau de complexidade interessante: edifícios altos, com atuação da carga do vento e consideração de core-wall no sistema de contraventamento (Figura 9); pórtico verticais em madeira com infraestrutura em concreto armado e contraventamento com treliças verticais posicionadas na fachada, usando os elementos estruturais como parte da composição arquitetônica (Figura 10); edificações não tão complexas, mas contendo todos os elementos estruturais, sistemas diferentes se relacionando entre si e a contabilização do nível de consumo de material estrutural para comparação com níveis usuais (Figura 11). 
SILVA, F. T. da.

Experiências com ferramentas digitais no ensino de estruturas arquitetônicas

Figura 7 - Maquetes e protótipos de pavilhões de estruturas funiculares, Fase 3

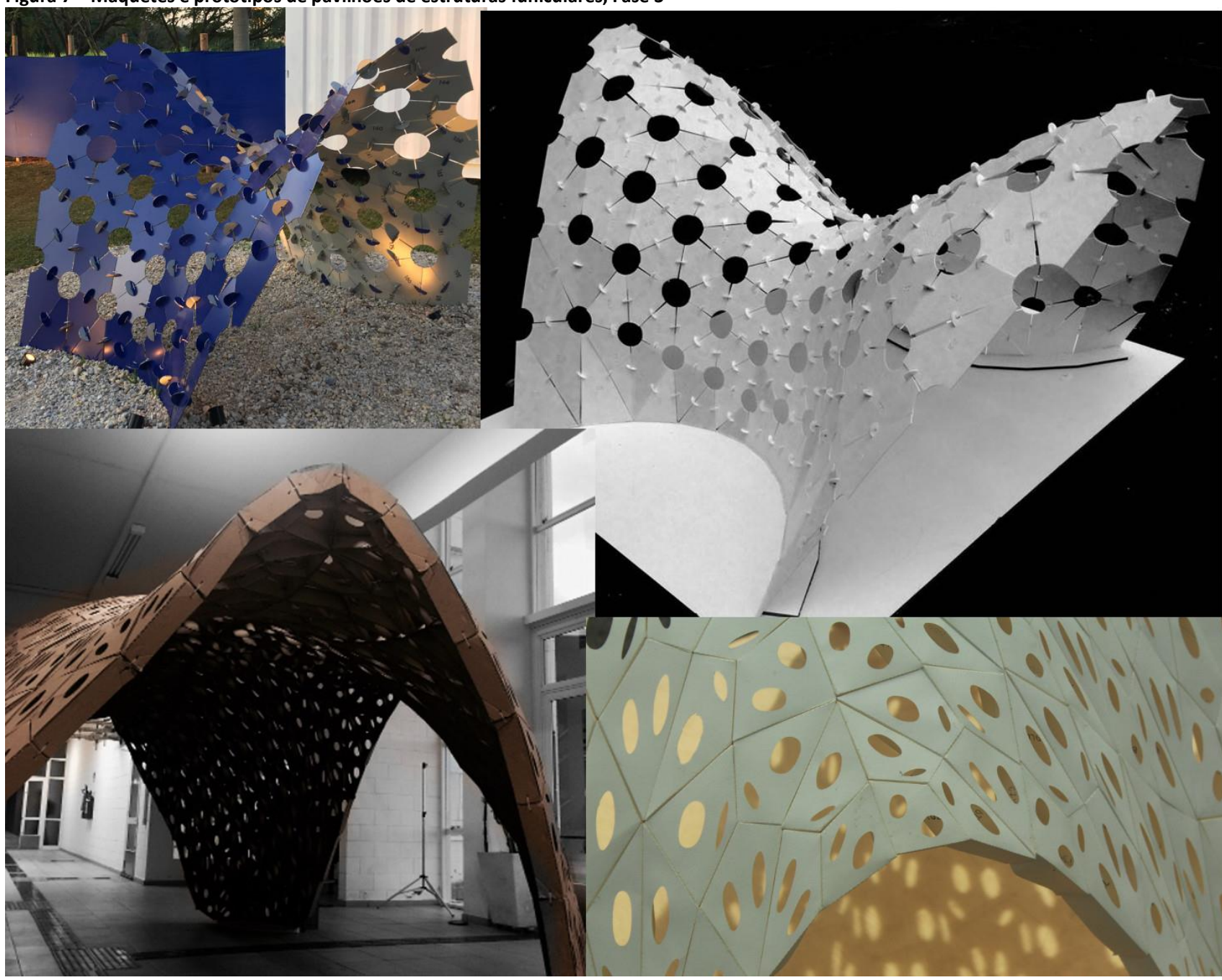

Nota: Protótipo em ACM de forma em paraboloide hiperbólico (à esquerda acima), maquete 1:3 (à direita acima), Protótipo em papelão de forma livre (à esquerda abaixo) e maquete 1:3 em papel cansson (à direita abaixo). Fonte: fotografias cedidas por Carol Sylos, Robson Canuto e Raquel Leite.

\section{Figura 8 - Modelagem Paramétrica e Fabricação Digital de pavilhões, Fase 4}

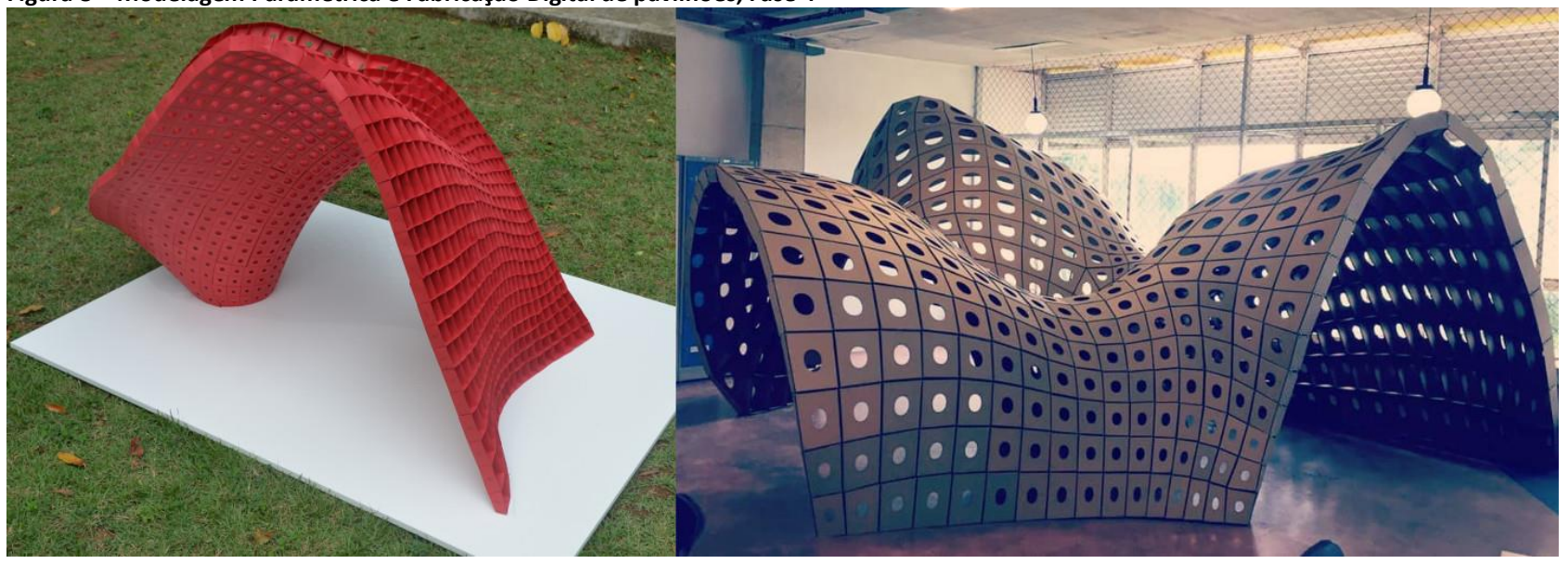

Nota: Maquete 1:3 em papel cansson de forma livre (à esquerda) e protótipo em papelão de forma livre (à direita). Fonte: fornecido e autorizado pelos alunos da equipe do trabalho. 
SILVA, F. T. da.

Experiências com ferramentas digitais no ensino de estruturas arquitetônicas

Figura 9 - Projeto de edifício vertical de médio porte em aço - Estruturas III, Fase 4
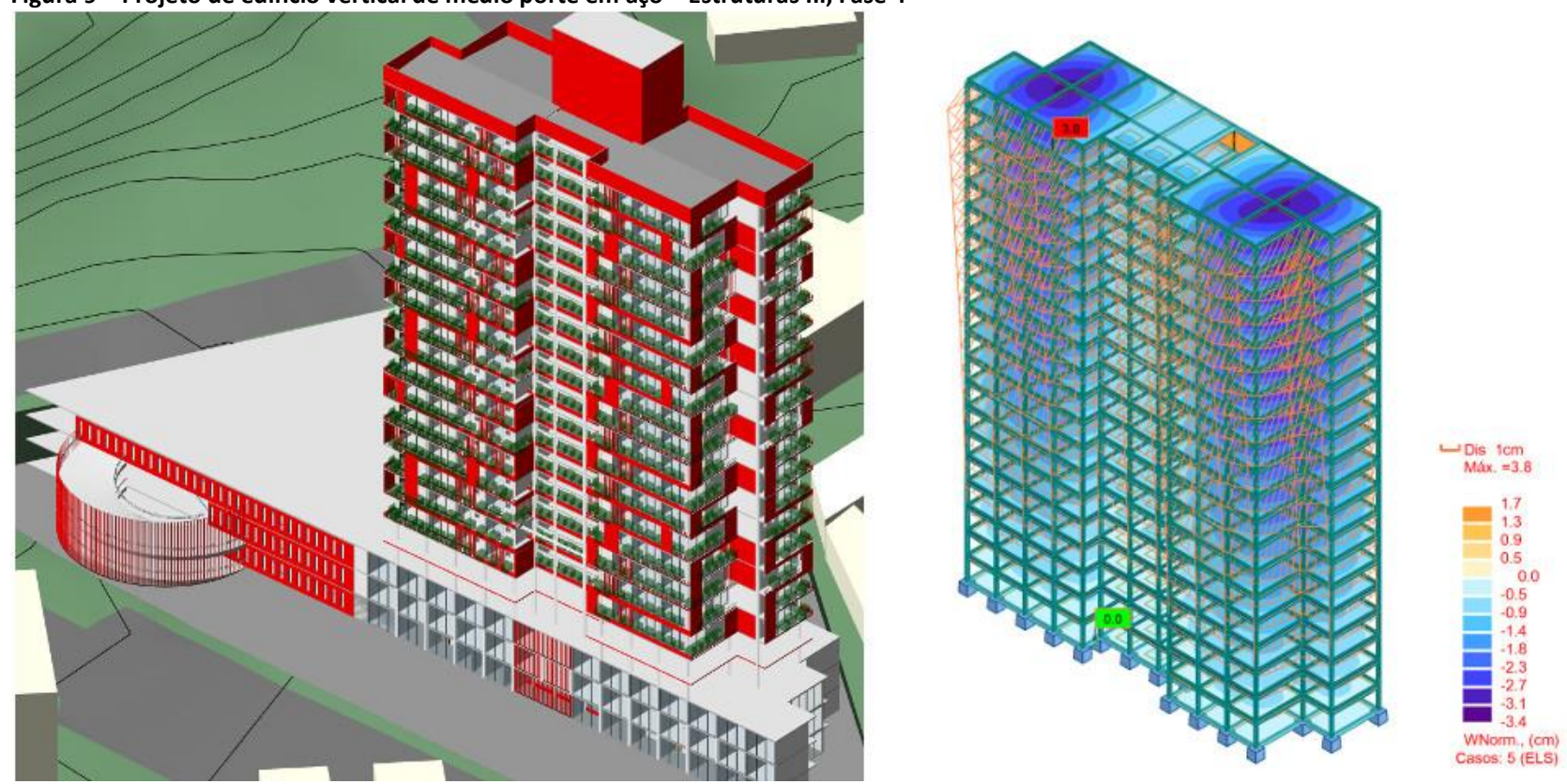

Nota: vista geral do edifício em modelo 3D (à esquerda) e vista geral do modelo estrutural (à direita). Fonte: fornecido e autorizado pelos alunos da equipe do trabalho.

Figura 10 - Projeto de edifício multi-pavimentos em madeira - Estruturas IV, Fase 4

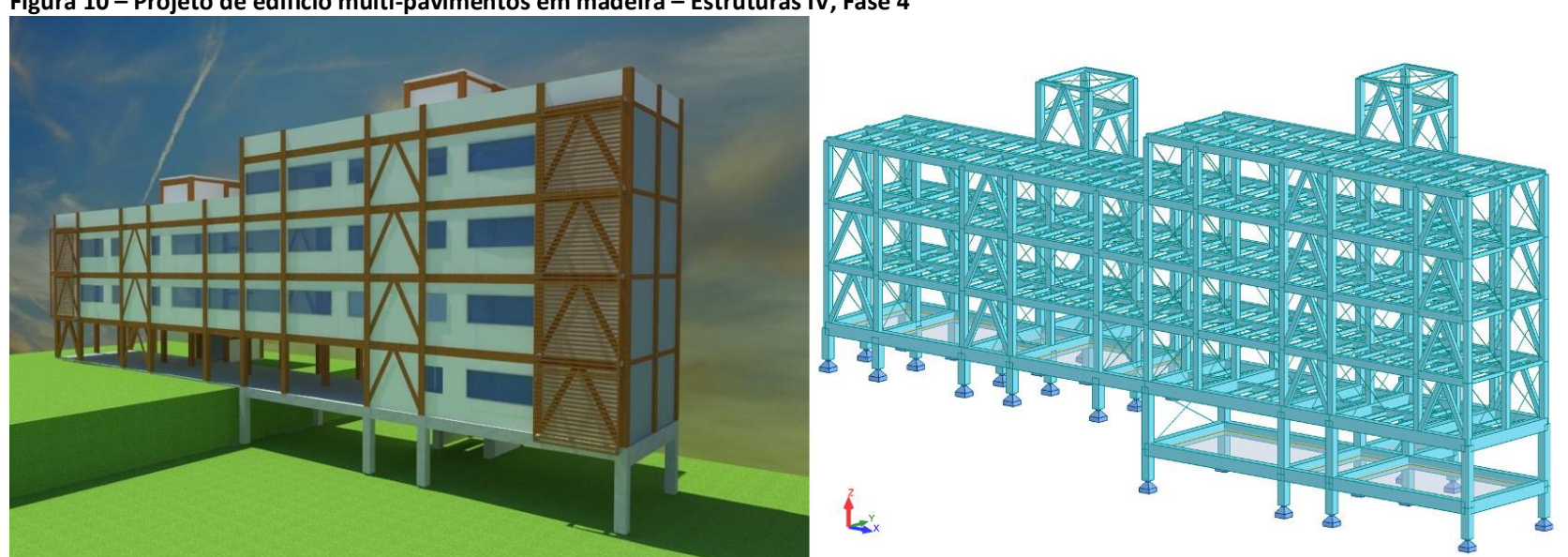

Nota: vista geral do edifício em modelo 3D (à esquerda) e vista geral do modelo estrutural (à direita). Fonte: fornecido e autorizado pelos alunos da equipe do trabalho.

Figura 11 - Projeto de edifício de médio porte em madeira - Estruturas IV, Fase 4

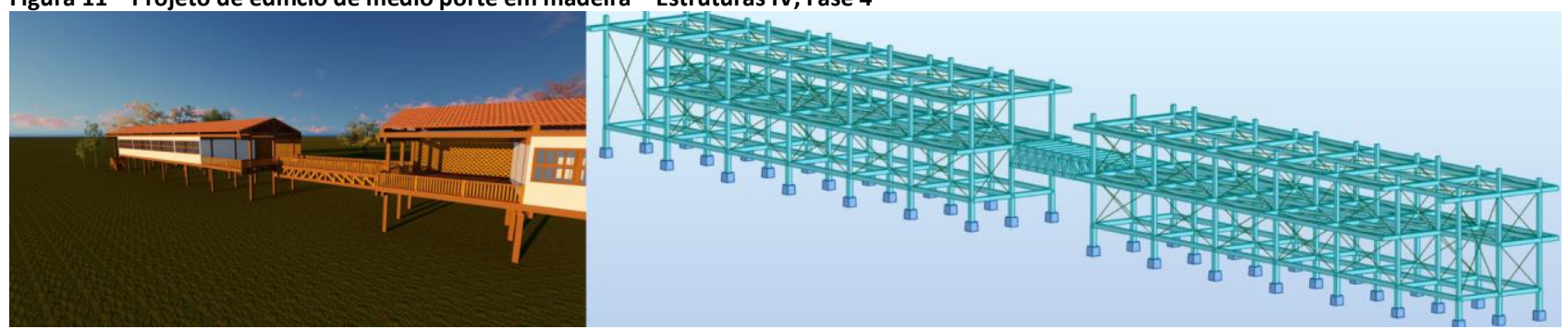

Nota: vista geral do edifício em modelo 3D (à esquerda) e vista geral do modelo estrutural (à direita). Fonte: fornecido e autorizado pelos alunos da equipe do trabalho.

Nesta experiência de ensino, uma série de mitos puderam ser desmistificados. A exemplo da suposta obrigatoriedade de o poço do elevador ser concebido em um tubo de concreto armado da fundação à cobertura, em todos os casos, ao invés de ser uma opção de torre de contraventamento. Questões sobre espessuras muito pequenas relacionadas com grandes vãos; espessuras e capacidades de escadas; esbelteza 
SILVA, F. T. da.

Experiências com ferramentas digitais no ensino de estruturas arquitetônicas

elevada; dentre outros aspectos puderam ser abordados e melhor compreendidos pelos estudantes.

\section{Discussão e conclusão}

Esta experiencia de ensino revelou o valor do uso das tecnologias computacionais para o ensino de Estruturas em cursos de Arquitetura, e em capacitar futuros arquitetos a conceberem formas mais seguros da sua viabilidade técnica, construtibilidade e durabilidade. Nas fases preliminares de projeto, a capacidade de desenvolver ensaios a partir dessas tecnologias digitais permitiu retroalimentar o processo criativo de projeto.

Oficinas de MP e FD de pavilhões demonstraram ser ume excelente exercício prático de projeto, fabricação e montagem de formas que podem possuir uma função arquitetônica, promovendo a integração entre as disciplinas envolvidas no projeto e fabricação e implantação da construção.

Foi observado que devido ao fato de alunos modelarem e simularem a estrutura que desejam conceber para a sua proposta arquitetônica, verificando sua viabilidade mecânica-estrutural e quantificação de materiais, possibilitou que estes tivessem mais confiança da viabilidade técnica e financeira de suas concepções projetuais.

Esta autonomia por parte dos estudantes sobre a própria verificação da viabilidade técnica de suas proposições de concepção proporcionou uma profícua aproximação das atividades ao conceito do novo estruturalismo da Rivka Oxman (2010), trazendo a concepção estrutural para as fases iniciais do projeto arquitetônico do edifício, provendo maior oportunidade de harmonizar a coexistência dos sistemas prediais. Este feito representa uma contribuição sobre o ensino de estruturas para estudantes de arquitetura e insere o ensino de estruturas na arquitetura dentro da discussão contemporânea sobre trabalho projetual colaborativo e transdisciplinar sem perder de vista o desempenho do produto projetado.

Apesar das disciplinas específicas de projeto e detalhamento de estruturas em concreto armado (Estruturas II), aço (Estruturas III) e madeira (Estruturas IV) puderem trazer a perspectiva material-estrutura-forma preconizada por Rivka Oxman, ainda se observou um descompasso diante da concepção arquitetônica desenvolvida na disciplina de projeto de arquitetura, que não seguiu essa lógica na grande maioria dos casos. Este fato trouxe alguma dificuldade em integrar o projeto ou conduzi-lo sem nenhum retrabalho, sugerindo que uma maior integração ou comunicação na estrutura curricular dos cursos de graduação em Arquitetura poderia ser altamente positiva neste aspecto.

Com esta experiência, propõe-se aqui entender que um conjunto de disciplinas de estruturas para o ensino em cursos de Arquitetura deveria iniciar com uma disciplina básica que aborde: o uso de modelos físicos deformáveis para observar modos de deformação elásticas e composição hierárquica de sistemas estruturais simples; apresentação de tipologias clássicas de sistemas em diversas escalas e sua adequação a melhor faixa de vãos; a relação entre forma estrutural e forma arquitetônica; noções básicas de pré-dimensionamento; e a proficiência em mecânica estrutural básica o suficiente para realizar simulações estruturais e verificar aos Estados Limites. As disciplinas seguintes poderiam aprofundar o conhecimento específico das estruturas em seus materiais tradicionais: concreto armado; aço; e madeira; pensando em concepções a partir do material, adequando-se à Arquitetura nas fases preliminares de projeto e chegando ao detalhamento de forma automatizada. Uma maneira de se evitar um grande número de disciplinas de estruturas (superior a quatro) poderia ser integrar estas disciplinas com as de projeto arquitetônico e de MP, unificando os mesmos exercícios nessas disciplinas. Assim, os alunos poderiam explorar com mais 
SILVA, F. T. da.

Experiências com ferramentas digitais no ensino de estruturas arquitetônicas

profundidade e qualidade o mesmo exercício de projeto em algumas disciplinas concomitantes de forma integrada e especializada.

Foi observado que a discussão sobre a viabilidade técnica das estruturas com os alunos é extremamente prejudicada quando estes não têm a noção sobre os Estados Limites, e por não operarem simulações estruturais não podem realizar essas verificações por conta própria. A discussão sobre algumas concepções estruturais, sobretudo em formas mais ousadas ou complexas, torna-se muitas vezes inconclusiva sobre a suficiência das dimensões das espessuras das peças estruturais. Estes acontecimentos reforçam o entendimento da necessidade de implementação de ensino de simulação estrutural em disciplinas de Estrutura para Arquitetura, capacitando melhor o estudante de Arquitetura em propor uma forma viável tecnicamente ou pelo menos melhorando a qualidade de sua compreensão sobre a concepção, projeto e detalhamento estrutural, necessário para que este integre uma equipe transdisciplinar de projeto de edifícios.

Outro aspecto que também foi observado foi que todos os professores de projeto de Arquitetura foram formados em épocas onde não se usava corriqueiramente simulações estruturais ou de outra natureza que utilize o computador. Além disso, a compreensão de como se deve ser o processo de projeto transdisciplinar não parece estar suficientemente clara na bibliografia, além das indicações de Kolarevic e Oxman, sendo observada uma dificuldade de se conceber uma metodologia de processo de projeto que se adeque à situação ou ao ferramental disponível atualmente para o trabalho.

Neste artigo foi trazida uma discussão sobre as ferramentas digitais e usadas como recursos de ensino de estruturas para a Arquitetura, utilizando esta discussão para embasar a observação da experiência de nove anos de ensino de estruturas na arquitetura implementando ferramentas computacionais. Pode-se dizer que o uso de simuladores estruturais aliada a uma noção básica de mecânica, resistência dos materiais e Estados Limites, dão a condição para todos os estudantes e talvez qualquer projetista de Arquitetura para verificar a viabilidade mecânica de sua proposição de uma determinada forma arquitetônica. Esta habilidade inseriria este profissional em uma condição de participar de uma equipe transdisciplinar juntamente com um engenheiro de estruturas e demais envolvidos no projeto, minimizando os ciclos circulares infindáveis de modificações durante o desenvolvimento de um projeto. Além disso, possibilita também, dentro das atribuições legais do Arquiteto no Brasil de acordo com o CAU, possibilitá-lo a conceber, projetar e detalhar uma estrutura arquitetônica.

\section{Agradecimentos}

O autor agradece a todos os alunos que fizeram parte desta jornada, em especial aos que cederam as imagens de seus trabalhos para ilustrar a produção deste período de experiência de ensino-aprendizagem.

\section{Referências}

ALLEN, E.; IANO, J. The architect's studio companion: rules of thumb for preliminary design. 6. ed. New Jersey: John Wiley and Sons, 2017. $410 \mathrm{p}$.

BIALKOWSKI, S. tOpos: GPGPU Accelerated Structural Optimisation Utility for Architects. In: ANNUAL CONFERENCE OF EDUCATION AND RESEARCH IN COMPUTER AIDED ARCHITECTURAL DESIGN IN EUROPE, 35, 2017, Roma.

Proceedings [... ]. Roma: ECAADE, 2017. p. 679-688, v.1. Disponível em: http://papers.cumincad.org/cgibin/works/Show?ecaade2017_099. Acesso em: 14 de agosto 2021.

BRITO, B. L.; SILVA, F. T. Estudo paramétrico de sistemas de piso bidirecional e unidirecional modulados em concreto armado. In: ENCONTRO DE TECNOLOGIA DE INFORMAÇÃO E COMUNICAÇÃO NA CONSTRUÇÃO. 7., 2015, 
SILVA, F. T. da.

Experiências com ferramentas digitais no ensino de estruturas arquitetônicas

Recife. Anais [...]. Porto Alegre: ANTAC; São Paulo: Blucher, 2015. p. 142-155. DOI: https://doi.org/10.5151/engprotic2015-013 ",

BRANCHIER, H.S. Contribuições dos softwares na aprendizagem de análise e cálculo de elementos estruturais. 2017. 110f. Trabalho de conclusão de curso (Curso de Engenharia Civil) - Universidade do Vale do Taquari, Lajeado, 2017.

CHING, F.D.K.; ONOUYE, B.S.; ZUBERBUHLER, D. Sistemas estruturais ilustrados: padrões, sistemas e projeto. 2. ed. Porto Alegre: Bookman, 2015. 352 p.

CORKILL, P.A. Preliminary Structural Design Charts for Architects. Architectural Science Review, v. 12, n. 1, p. 15-20, 1969. DOI: https://doi.org/10.1080/00038628.1969.9696256

DRESCH, A.; LACERDA, D. P.; ANTUNES JÚNIOR, J. A. V. Design Science Research: Método de pesquisa para avanço da ciência e tecnologia. Porto alegre: Bookman, 2015. 181 p.

ENGEL, H. Sistemas Estruturais. 1. ed. Barcelona: Gustavo Gili, 2001. 352 p.

HOLZER, D. Design exploration supported by digital tool ecologies. Automation in Construction, v. 72, Part 1, p 3-8, 2016. DOI: https://doi.org/10.1016/j.autcon.2016.07.003

KOLAREVIC, B. Architecture in the Digital Age. 1. ed. New York: Taylor \& Francis, 2003. 441 p.

KOLAREVIC, B. Towards Integrative Design. International Journal Of Architectural Computing, v. 7, n. 3, p. 335-344, 2009. DOI: https://doi.org/10.1260/147807709789621248

LOBOSCO, T.; CÂMARA, D.C. Desenvolvimento de modelos qualitativos para o ensino de estruturas. PARC Pesquisa em Arquitetura e Construção, v. 9, n. 3, p. 167-178, 2018. DOI: https://doi.org/10.20396/parc.vgi3.8650263

MACDONALD, A. J. Structure and Architecture. 2. ed. Oxford: Architectural Press, 2001.164 p.

MICHALATOS, P. Millipede for Grasshopper discussion List. Disponível em

http://www.grasshopper3d.com/group/millipede, Acesso em: 14 de março de 2021.

MARSH, K. Autodesk Robot Structural Analysis Professional 2016 Essentials. 1. ed. Sommerville: Marsh API LLC, 2015. $536 \mathrm{p}$.

MORA, R.; BEDARD, C.; RIVARD, H. A geometric modelling framework for conceptual structural design from early digital architectural models. Advanced Engineering Informatics, v. 22, p. 254-270, 2008. DOI: https://doi.org/10.1016/j.aei.2007.03.003

MOUSSAVI, F. The function of Form. 1. ed. Barcelona: ACTAR, 2009. 520 p.

OLIVEIRA, M. S. Modelo estrutural qualitativo para pré-avaliação do comportamento de estruturas metálicas. 2008. 172 f. Dissertação (Mestrado em Engenharia Civil) - Universidade Federal de Ouro Preto, Ouro Preto, 2008.

OXMAN, R. The New Structuralism: design, engineering and architectural technologies. Architectural Design, v. 80, n. 4, p. 15-23, 2010. DOI: https://doi.org/10.1002/ad.1101

POTTMANN, H.; EIGENSATZ, M.; VAXMAN, A.; WALLNER, J. Architectural Geometry. Computers \& Graphics, v. 47, p. 145-164, 2015.

PREISINGER, C.; HEIMRATH, M. Karamba: A Toolkit for Parametric Structural Design, Structural Engineering International, v. 2, p. 217-221, 2014. DOI: https://doi.org/10.2749/101686614X13830790993483

REBELLO, Y. C. P. Bases para o projeto estrutural na arquitetura. 1. ed. São Paulo: Zigurate Editora, 2007. 288 p. 
SILVA, F. T. da.

Experiências com ferramentas digitais no ensino de estruturas arquitetônicas

SANDAKER, B. N. On Span and Space: exploring structures in architecture. 1. ed. New York: Routledge, 2007.212 p.

SARAMAGO, R. C. P. Ensino de estruturas nas escolas de arquitetura do Brasil. 2011. Dissertação (Mestrado em Arquitetura, Urbanismo e Tecnologia) - Escola de Engenharia de São Carlos, Universidade de São Paulo, São Carlos, 2011. DOI: https://doi.org/10.11606/D.18.2011.tde-31052011-101630

SANTOS, D.P.; SILVA, F.T. Pré-dimensionamento paramétrico de pórticos de aço em perfis conformados a quente de abas paralelas. In: CONGRESSO LATINO-AMERICANO DA CONSTRUÇÃO METÁLICA, 7, 2016, São Paulo. Anais [...]. São Paulo: ABCEM, 2016. p. 1-21. Disponível em: https://www.abcem.org.br/construmetal/downloads/Anais-do-7Construmetal2016-EBook.pdf. Acesso em: 14 agosto 2021.

SILVA, F.T. Automatic structural preliminary design of a 3D concrete frame by numerical parametric structural modeling. In: CELANI, G.; KANOUN, O. Frontiers of Science and Technology: Automation, Sustainability, Digital Fabrication - Selected Extended Papers of the 7th Brazilian-German Conference, Campinas: DE Gruyter, 2017a. DOI: https://doi.org/10.1515/9783110537680-015

SILVA, F. T. Concepção Interativa e Parametrizada de Edifícios de Múltiplos Pavimentos em Concreto Armado. Gestão \& Tecnologia de Projetos, v. 12, n. 1, p. 9-27, 2017b. DOI: https://doi.org/10.11606/gtp.v12i1.99212

SILVA, F.T. Modelo paramétrico de pórticos em concreto armado com dimensionamento otimizado: uma proposta de ferramenta de projeto para as fases iniciais de concepção estrutural. Ambiente Construído, v. 18, n. 1, p. 193-210, 2018. DOI: https://doi.org/10.1590/s1678-86212018000100216

SOLLY, J.; FRÜH, N.; SAFFARIAN, L. A.; MARGARITI, G.; KNIPPERS, J. Structural design of a lattice composite cantilever. Structures, v. 18, p. 28-40, 2019. DOI: https://doi.org/10.1016/j.istruc.2018.11.019

STEWART, R. Building on the advantages of composites in construction. Reinforced Plastics, v. 54, n. 5, p. 20-27, 2010. DOI: https://doi.org/10.1016/So034-3617(10)70171-5

TAVARES, Felipe. Planilhas automáticas para pré-dimensionamento e dimensionamento estrutural. https://doi.org/10.5281/zenodo.5213914. Zenodo. V. 1. 17 ago. 2021.

TEDESCHI, A. AAD Algorithms-Aided Design: Parametric strategies using Grasshopper. 1. ed. Brienza: Le Penseur Publisher, 2014. 496 p.

WONOTO, N. Integrating Parametric Structural Analysis and Optimization in the Architectural Schematic Design Phase. 2017. 293f. Tese (Doutorado em Planejamento, Projeto e Ambiente Construído) - Clemson University, Clemson, 2017.

\section{Felipe Tavares da Silva}

Engenheiro Civil. Doutor. Professor do Departamento de Arquitetura e Urbanismo da Universidade Federal da Paraíba. Centro de Tecnologia. Endereço postal: Cidade Universitária, sn, João Pessoa, PB - Brasil. CEP 58051-900 